that had been made in school teaching since the "Euclidean" days, and the gradual recognition that mathematics is a single co-ordinated subject, where it is possible to introduce such topics as analytical geometry and calculus long before algebra and geometry had been carried to the limits of school achievement.

Prof. H. Levy dealt mainly with the teaching of applied mathematics, at the university-level, to students of various faculties. He pressed the view that diagrams on paper and blackboard should be realistically seen for what they are-simplified physical 'models' in chalk or carbon particles of actual things. Already, even at this stage, irrelevant elements in the medley of events in the real world have been dropped out, and from this rather grotesque model, sticking to an almost flat surface, it becomes relatively easy for the student to make the mental abstractions we call lines, curves and points. Mathematics, he asserted, deals in the first instance only with these abstractions, and in this way the mathematician sets out to develop a logical deductive system in place of the actual physical process that is being studied. The laws of Nature-Newton's laws, for example-are extracted and abstracted from the medley of real objective events 'out there', and enter as mere mathematical assumptions into the logieal analysis. It is important for a student to see this clearly in order to undermine the 'mystique' of a mathematically derived formula, and to underline the fact that its validity finally rests on verification by observation or experiment, and not merely on logic. In all this, imagination plays a very important part. To construct the appropriate 'model' on paper or blackboard, from the physical sequence of events, requires a considerable effort of the imagination; just as the sense of logical conviction itself rests on a mental scrutiny of imagined alternatives at each step of a proof.

From this point of view Prof. Levy sharply criticized the usual sets of examples and exercises in text-books, in which the author himself has already made the principal geometrical abstraction, expressing it through the phrasing of the question, while the dynamical principle that is to be used in the logic is made obvious from the place of the example in the text-book. While not undervaluing that kind of 'drill', he insisted that teaching and learning are simply two aspects of one process in which both teacher and student are engaged. It follows from this that the teacher must be seen by the student to wrestle with a problem, and, if necessary, to be beaten. The problem must be real, and not a faked-up one designed to come out. Preferably, it should be brought by the student out of his own experience so that the successive steps in forming the abstrac. tions may become apparent. Familiarity with both geometrical and dynamical abstractions plays a significant part in pointing the way towards this reduction of actual physical problems to those of logic. Finally, the precise verbal formulation of the problem in concise terms, as it would appear in a text-book, is itself a crucial educational step. Prof. Levy concluded by stating that in his view it was desirable that every mathematical department should have available as many bits of machines as possible, in order that the student should take them to pieces and re-assemble them, and so seek to isolate the dynamical factors that appear to be in operation during their functioning. In this way the geometrical and dynamical abstractions that require to be made in order to analyse the process from the mathematical point of view would become apparent. This kind of training, consciously applied and consciously appreciated by the student, was essential if he was to play his part qua mathematician in modern industry.

Dr. E. A. Maxwell turned to the problem of the teaching of pure mathematics, and in particular he raised the question by what process could the student be encouraged from the beginning to appreciate the importance of rigorous and accurate thinking, and, as part of this, the specific limitations under which the theorems he was using were valid. To this end he stressed the educational value of using the method of contradiction, in a direct form, by 'proving' a number of propositions of the $2=1$ type, for the purpose of intriguing the student in the first place. As a consequence, his interest is enlisted in discovering where and how precisely the limitations of the method used have been overstepped. This he illustrated with a variety of examples from a wide range of mathematics. An excellent discussion followed a most interesting morning session.

\title{
PHYSIOLOGY AS AN EDUCATION AND AS A CAREER
}

A JOINT session of Section I (Physiology/Biochemistry) and Section $L$ (Education) of the British Association and of the Physiological Society, held in the Institute of Physiology, University of Glasgow, on September 3, was devoted to a discussion of "Physiology as an Education and as a Career".

In the absence of Prof. A. V. Hill his introductory remarks were read, with evident sympathy and signal effect, by one of his former junior colleagues, Prof. R. W. Gerard, of the Department of Physiology, University of Michigan. Prof. Hill began by recalling what he had said on this topic on several occasions from the 1920's onwards. In these he emphasized the need to free physiology from the bedside attachment of its earlier years and allow it to come in its own right to full stature, as the interpretation of the mechanisms and integrations of normal life. Thus physiology would be brought into a wider service of mankind in the modern fully industrialized State. It has become necessary to spread into now fields the knowledge of the "exquisite structure of the body" and the proper understanding of its functional capabilities and limitations. In all this there is need for first-class brains because in the biological field the data are much more intractable than are those in the inorganic field. This battle for the status of physiology in its own right is slowly being won. Much could be done by capturing early the imagination and interest of the young and securing recruits by means of practical demonstrations and teaching in the schools. 
Prof. Hill's Royal Institution Christmas Lectures, later published as "Living Machinery" (Bell ; 1927), have shown just how successful this could be.

Dr. J. A. B. Gray (University College, London), who read a paper on "Physiology in Universities", also stressed the emancipation of physiology from its ancillary position in medicine. Physiology is the study of the mechanisms of living species and can be studied at different levels, in cells, in tissues, in organs, in systems and in individuals. It can be applied, not only to man in his life in a more or less normal community, but also to man at the summit of Everest and at the South Pole. It also extends over the widest limits of the comparative field from bacteria to man. $\mathrm{He}$ pointed to the growth of physiology as a subject in the faculty of science in one-year, two-year and honours courses. This field offers a unique opportunity for experiment and for the application of physics and chemistry to the fundamental processes of all living organisms. There is opportunity for a much fuller study of man in his place in the modern industrial and engineering world, in the design of instruments and machines to be operated by men and in the determination of the limiting factors in efficiency and endurance in new environments. Much closer links should be forged with psychology ; philosophers, too, might profit from a course in physiology.

Thus while physiology must remain as an essential introduction to clinical medicine-the Institutes of Medicine-there are many reasons why ample provision should be made in every university for such courses in the faculty of science to meet other urgent needs.

Mr. H. P. Ramage (Gresham's School, Holt), dealing with "Physiology in Schools", spoke with obvious feeling and emphasis on the pressing need for a balanced education, not just as between science and the other subjects but within the field of science itself. Looking back to the findings of a Royal Commission of 1864 where the place of biology in schools was recognized, he pointed to the very small number of schools, and particularly boys' schools in Britain, where biology takes its proper place in the science curriculum. Biology is, he maintained, a necessary part of general science and general science a necessary part of general education. It is important to realize the value of biology for those who later would not go on to university, as well as for those who would. Much too strong an emphasis is being placed on the inorganic sciences in schools and this gives an unduly mechanistic bias to the minds of the young. Too few biology teachers are available in the schools. The Science Masters' Association is preparing a policy statement in the hope of restoring balance to the present lopsided presentation of science in schools.

Dr. W. Cobb (National Hospital, Queen Square, London), speaking on "Physiology in Medical Research", used the story of Berger's early pure research into changes in electrical potential on the human cerebral cortex, later confirmed by Adrian, to demonstrate how a piece of pure research may later have an extensive practical application. The original research was the patient, disinterested and long unappreciated work of an individual. It was, however, to become in the hands of many others the electroencephalograph, a routine procedure of diagnostic value, widely used in many cerebral conditions. Such an example of the later development of practical applications of pure research is one of many. Physio- logy will continue to discover new procedures which will later have quite unforeseen usefulness in other fields.

In neurology Dr. Cobb felt that too little work in cerebral physiology is being done in Britain. There is still a gulf, relatively unbridged, between the traditional clinical observational neurologist after the pattern of the great neurologists of the past, and the modern neurophysiologist trained in electronic techniques.

Dr. D. P. Cuthbertson (Rowett Research Institute, Aberdeen) read a paper entitled "Careers for the Physiologist in Agricultural Research". On the successful application of science to agriculture, which is the basic industry in Britain, Dr. Cuthbertson maintained, our future depends; and in this application, physiology has a foremost place. In agricultural research much has been done but much more remains to be done in the extension and orientation of physiological methods to urgent problems. As an example he described briefly the fascinating set of problems associated with digestion in the ruminants, where the problems of animal digestion are complicated by those of microbiology. He did indeed suggest that the physiologist who wishes to enter agricultural research should have a preliminary training in microbiology. He directed attention also to the need for extensive environmental studies, as for example the basic work being done at the Hannah Dairy Research Institute on temperature regulation in cattle. Another expanding area is that associated with the use of insecticides, where problems branch out into many other fields. There are other urgent questions pressing for solution, but where, asked Dr. Cuthbertson, are the physiologists?

Dr. J. Yule Bogue (Pharmaceuticals Division, Imperial Chemical Industries, Ltd.) spoke on "Physiologists in Industry".

Industry has to undertake research, some of it of a fundamental nature, in its efforts to further its own strictly practical aims, for example, the preparation of new pharmaceutical products. In a university post, the young physiologist has to combine research with teaching: in industry he or she has to link together research and routine testing. Just as good research in universities is associated with and indeed stimulates good teaching, so good research in industry is associated with good routine work and might indeed find in it interesting new problems. Physiologists in industry are faced with two groups of questions requiring solution. (a) Problems of environmental physiology, for example, in the determination of the conditions in industry which make for maximal efficiency : how man may best be protected from hazards of many kinds, or how the design of instruments may give the least possible fatigue, etc. In this group the medically qualified physiologist is essential. (b) Problems which emerge in the study of the action of new products and in the search for further products. These are largely dependent on comparative physiology and may range widely : a medical qualification is not required.

As a preparation for industrial work a wide general physiological experience is best; specialization can be provided in the industry itself when necessary. Dr. Bogue refuted the suggestion that the scientific staff may be under pressure from the management : rather it is a question of the research colleagues supplying the incentive. Generous provision is made in industry for the scientific staff to attend and take part in academic and scientific societies. 
Reading a paper on "The Training of Physiologists", Prof. D. H. Smyth (University of Sheffield), who has had a lifelong interest in educational problems, began by speaking of the two different types of individual who might take up physiology as a career. One is the mathematically-minded person who, perhaps, shows his true bent in his hobby of taking the family car to pieces and putting it together again. The other is the biologically-minded individual whose leisure time has been for years expended in early nature studies and who later becomes the serious birdwatcher, fisher or amateur botanist, for he is essentially an outdoor type. While the biologically-minded type is better equipped to see the real physiological problem and has much more highly developed powers of observation, it is the mathematically-minded type who would in the end make a satisfactory analysis of the problem and offer an adequate mathematical solution. In direct contrast to Mr. Ramage, Prof. simyth was inclined to question the value of biology as a subject in the school curriculum. It is unfortunate that the educationists are as a rule inclined to put their bright pupils into physics and chemistry and the less bright into biology. What is needed is a combination of a good mathematical training and a driving interest in living organisms and how they function. Without the essential motive the more mechanically minded may become just purveyors of gadgets.

In the general discussion that followed these short papers, a questioner was assured that up to the present no difficulty has been experienced in placing women graduates in physiology, and also that no discrimination against women with first-class honours degrees exists in industry.

Dr. Bogue stressed the fact that recently graduated candidates would only be accepted for research by Imperial Chemical Industries, Ltd., if they had first-class honours degrees. $\mathrm{He}$ made it clear, however, that many second-class honours graduates were used in the more routine technical work. In his experience industry had found it well worth while to give a first-class honours chemistry graduate as much as three years special training in physiology or pharmacology to get the individual they wished.

There appears to be little accurate knowledge available of the actual number of posts open to physio- logists in Britain. In view, however, of the number of unfilled vacancies there seemed to be no likelihood of over-crowding within the next few years. Dr. Gray spoke of even third-class honours graduates having no difficulty in finding suitable work.

Prof. Gerard then spoke of his own interest in this question and in the survey made recently by a committee in the United States, and published under the title "Mirror to Physiology". He discussed the status of physiologists in America and the need for more physiologists there, and also for an improvement in the standards of the lower levels of physiology teaching.

Dr. R. H. Noltie directed attention to the development of physiology teaching in university and college departments of biology and zoology, in isolation from the traditional physiology departments.

The discussion closed with some telling remarks by Sir Charles Lovatt Evans. He reminded the meeting of the difference in rate of development which often means that the good second-class honours man eventually became the first-class researcher who makes the real advances in our knowledge. It was not always true that the first-class honours man became the first-class research worker. Sir Charles thought also that the present concern in many circles for technology and technicians is not without its dangers. Science is a way of thinking and technology is a way of doing things. In his view, there can be no doubt which is the more important.

Thus several points emerged which merit consideration at a future date : (1) The value of the teaching of biology in schools, including some elementary physiology, to all those who will not proceed later to university ; (2) the place of biology beside chemistry and physics in the school programme for those who will eventually go to a university ; (3) the integration of the teaching of physiology in colleges and universities where this is now being done outside the departments of physiology ; (4) the need for a survey of the number of physiology graduates required each year not only in the traditional physiology college and university departments but also throughout the whole field, so that training may be geared to the numbers required and diversified to meet the various new demands.
H. S. D. Garven

\section{SEMICONDUCTOR RESEARCH}

$I^{N}$ the ten years that have elapsed since the invention of the transistor, the close interaction between academic interest and industrial requirements in the semiconductor field has led to the growth of many industrial and government laboratories with interests in this subject. Because of the connexion with academic work, these laboratories were readily able to grow by attracting graduates of suitable calibre. This has naturally led to much research activity in the semiconductor field, and this is nowhere moro pronounced than in the United States. There the transistor was invented, and there alone has it been marketed competitively. It was therefore appropriate that the bi-annual international conference on semiconductors should at last be convened in the United States, having previously met in Britain, Holland and Western Germany. The attractive and spacious campus of the University of Rochester was selected, and the meeting was held during August 18-22 under the chairmanship of John Bardeen. Almost all centres of semiconductor research were represented.

Even with the restrictions placed by the organizers on the number of papers read at the conference, their detailed discussion is not possible here. The general headings have not changed very much since the last meeting in $1956^{1}$, but some changes of emphasis have occurred in the interim and will now be surveyed.

Excitons. There was considerable interest in excitons at the 1956 meeting, with particular reference to the pioneer work of E. F. Gross (Leningrad) and S. Nikitine (Strasbourg), who had noted exciton spectra. Their experiments, which were still questioned in 1956, have now been largely accepted, 